\title{
Socio-economic Analysis and the Study of Prevalence, Awareness, Treatment, Control and Risk Factors of Hyperten- sion in Hospital Staff
}

\author{
Shakya $S^{*}$, Bhattarai $J^{*}$, Rawal K*, Kunwar AR*, Shakya YR*, Sharma $D^{*}$ \\ *Shahid Gangalal National Heart Centre, Bansbari, Kathmandu.
}

\section{ABSTRACT}

Hypertension is an important public health challenge in the developing and the developed world alike. This worksite based descriptive cross-sectional study was undertaken in Sahid Gangalal National Heart Centre in 2010 with 50 subjects were recruited by multistage purposive cluster sampling. The primary aim of this descriptive cross-sectional study was to assess the socioeconomic status and to measure the prevalence, awareness, treatment, and correlates of hypertension. The prevalence of pre-hypertension is $38 \%$ and hypertension is $34 \%$. Among the hypertensive $53 \%$ are aware of their condition and $66.66 \%$ of them are under treatment and $16.66 \%$ have control over the condition. The prevalence of overweight and obesity were $22 \%$ and $4 \%$ respectively. The prevalence of central obesity was $29.72 \%$ among male and $69 \%$ among female. Knowledge, Attitude and Practice on hypertension was satisfactory. Fourteen percent understood hypertension as a raised blood pressure during blood flow in the arteries. Majority of them $(72 \%)$ have positive attitude towards use of medicine in hypertension. Majority of them $(86 \%)$ had checked their blood pressure in last 2 years. Difference in prevalence of hypertension was found among the tobacco users and non- users ( $65 \%$ vs $40 \%$ ), who do regular exercise and those who do not $(28 \%$ vs. $38 \%$ ) and sleep disturbance was higher among hypertensive than non-hypertensive (48\% vs. $10 \%)$. Patients with Dislipidemia (32\%) had higher prevalence of hypertension than those without Dislipidemia (44\% vs $30 \%$ ) Similar finding were found between overweight participants (26\%) and normal weight participants ( $46 \%$ vs $34 \%$ ). The prevalence of hypertension is higher with the higher socio-economic status.

Key Words: Socio-economic status, Hypertension, Risk factors

Correspondence:

Samjhana Shakya,Senior Staff Nurse

Sahid Gangalal National Heart Centre

Bansbari,Kathmandu, Nepal

Phone Number: 00977-1-4371374

Email:shakyasamjhana@gmail.com 


\section{INTRODUCTION}

Hypertension is one of the most important causes of cardiovascular morbidity and mortality. Globally, 7 million people die every year because of hypertension ${ }^{1}$. About half of the world's burden of cardiovascular disease is carried by countries in the Asia- Pacific region. ${ }^{2}$ In Nepal, the prevalence of hypertension was $6 \%$ in rural Kathmandu ${ }^{3}$. One other study reported the prevalence of hypertension as $19.7 \%$ in the sub urban area of Kathmandu 4 .

Socioeconomic status is an important factor that determines the lifestyle, knowledge, attitude and practices of the people. It can have causative association and can interfere with treatment and treatment compliance .In developed countries socio economic condition is inversely associated with hypertension. However in low and middle income countries, section of the population that undergo more rapid social development are exposed to increased risk factors for CVD and thus are at a greater risk of disease compared to people who are less well off. ${ }^{5}$

This is a descriptive cross-sectional study done at a worksite. The objective of this study is to assess the socio-economic status of the respondents, assess the prevalence, awareness, treatment, control and risk factors of hypertension in the study population.

\section{METHODS}

A worksite based descriptive cross-sectional study was undertaken in Sahid Gangalal National Heart Centre in 2010 with all the staffs working under Department of Administration and Department of Finance. A Total of 50 subjects were recruited by multistage purposive cluster sampling. Data was collected in two months of time period from January 2010 to February 2010. By nature data are both qualitative and quantitative.

\section{INTERVIEW}

Interview with each subject was done by using structured and unstructured questionnaire. Informed consent was taken from each participant.

Measurement of Blood Pressure: Blood pressure (BP) measurement was carried out on each participant using standard mercury sphygmomanometers. BP was measured on both arms. Only the arm with higher BP was used for the second measurement. The first BP measurement was taken before the administration of the questionnaire and second BP measurement was obtained upon completion of the questionnaire. Mean Blood pressure was recorded on the basis of these two readings.

\section{Measurement of waist circumference:}

Waist circumference was measured according to the instructed by American Heart Association.

\section{Calculation of BMI:}

Height and weight was taken for each subject and $\mathrm{BMI}$ was calculated by weight in $\mathrm{kg}$ divided by height in meter square.

\section{RESULTS}

\section{Demographic Features}

There were altogether 50 respondents, male $37(74 \%)$ and female13 (26\%). The mean age of the respondent was $35.86 y e a r s$. Half of them had educated to less or equal to SLC and $48 \%$ had higher education. Majority of them live in single family $(68 \%)$. Twelve percent were vegetarians. Alcohol consumption and smoking were $54 \%$ and $48 \%$ respectively. One third of them do regular exercise.

\section{Basic Anthropometric Measurement}

Mean height and weight of respondents were $161.91 \mathrm{~cm}$ and $60.42 \mathrm{Kg}$ respectively. The prevalence of overweight and obesity were $22 \%$ and $4 \%$ respectively. The prevalence of central obesity was $29.72 \%$ among male and $69 \%$ among female.

\section{Prevalence, Awareness, Treatment and Con- trol of hypertension}

The SBP ranges from $95-170 \mathrm{mmHg}$ and DBP ranges from $65-110 \mathrm{mmHg}$. The average mean arterial blood pressure was $96.57 \mathrm{mmHg}$.The prevalence of pre-hypertension was $38 \%$ and hypertension was $34 \%$. Among the hypertensives, $53 \%$ were aware of their condition, $66.66 \%$ were on treatment and $16.66 \%$ of treated had controlled blood pressure.

Among hypertensive, $88.24 \%$ were male and 
$11.76 \%$ were female. $64.71 \%$ are younger than 40 years.

\section{Knowledge, Attitude and Practice}

Seventy percent of respondents knew at least two or more symptoms of hypertension. Fourteen percent understood hypertension as a raised blood pressure during blood flow in the arteries. $28 \%$ could able to give the value of normal blood pressure. Majority of them $(72 \%)$ have positive attitude towards use of medicine in hypertension. Majority of them (86\%) had checked their blood pressure in last 2 years.

Values of different parameters of hypertensive respondents $(n=17)$

\begin{tabular}{lc}
\multicolumn{1}{c}{ Parameters } & Percentage \\
\hline Central obesity & 41.81 \\
High BMI & 23.53 \\
Non Vegetarian & 94.18 \\
\hline Regular Exercise & 35.29 \\
Education less than SLC & 35.29 \\
Education more than SLC & 64.71 \\
\hline Job status : less than & \\
\hline administrative assistant & 35.29 \\
Job status : More or equal & \\
\hline to administrative assistant & 64.71 \\
\hline Joint family & 70.59
\end{tabular}

The prevalence of hypertension seems high with higher education, higher job status and Joint family.

\section{DISCUSSION}

The prevalence of pre hypertension was 38\% and hypertension was $34 \%$. We compare these findings, with two community based studies conducted in Nepal and two worksite based studies done out of Nepal.
Prevalence of hypertension in this study seems highest in compare to above study. We also found that the prevalence of pre hypertension has increased in many folds in this one decade. ${ }^{6}$

As all the participants of this study are hospital staff their awareness was higher than community based study. Even though, awareness seems poor in compare to previous study. ${ }^{7}$

Health seeking behavior on hypertension in this study was $67 \%$ compared to $26 \%$ in 2006 study. ${ }^{8}$

It can be concluded that, definitely prevalence of pre-hypertension and the hypertension is increasing. Awareness, control and treatment rate is higher than community based study conducted in sub urban area in Kathmandu (4)but it is poor in compare to study had done in Salami Factory. ${ }^{9}$

Knowledge, Attitude and Practice (KAP) on hypertension

Overall health seeking behavior of participants was very good. All of them have heard about the hypertension and $86 \%$ of them have checked their blood pressure within last two years. More than half of them $(58 \%)$ have given value for their last blood pressure. This figure is very good in compare to previous study when only $10 \%$ did $\mathrm{so}^{10}$.

Basic knowledge on hypertension was found very high. Seventy percentages of the participants knew at least two or more symptoms of hypertension. Only one of them said, hypertension only rarely causes any symptoms compared to $28 \%$ in above study.

Overall, KAP on hypertension was satisfactory among the participants. It may be because they are heart hospital staffs; they are more knowledgeable in compare to general public. So, this data may not be representing general public's KAP on hypertension.

\section{Lifestyle and Hypertension}

No significant differences were found between vegetarians and non- vegetarians, amount of salt and oil consumption, frequency and amount of fruits and vegetables consumption, nature of their work and leisure activity. It may be because of 


\section{Comparison of findings on Prevalence, Awareness, Treatment and Control of hypertension}

\begin{tabular}{lccccc}
\multicolumn{1}{c}{$\begin{array}{l}\text { Studies } \\
\text { Indicators }\end{array}$} & Sharma D(2006) & Vaidhya (2007) & Sankodi (2004) & Capriotti (2000) & Shakya (2010) \\
$\begin{array}{l}\text { Prevalence of } \\
\text { hypertension }\end{array}$ & $19.7 \%$ & $22.7 \%$ & $25.7 \%$ & $30 \%$ & $34 \%$ \\
Pre-Hypertension & $*$ & $*$ & $*$ & $11 \%$ & $38 \%$ \\
Awareness & $41.1 \%$ & $*$ & $61.5 \%$ & $4 \%$ & $53 \%$ \\
Treatment & $26 \%$ & $*$ & $*$ & $*$ & $66.66 \%$ \\
Control & $6 \%$ & $*$ & $21.9 \%$ & $*$ & $16.66 \%$ \\
\hline
\end{tabular}

inadequate subjects to prove it significant. Difference in prevalence of hypertension was found among the tobacco users and non- users (65\% vs $40 \%)$, who do regular exercise and not ( $28 \%$ vs. $38 \%)$ and sleep disturbance was higher among hypertensive than non-hypertensive (48\% vs. $10 \%)$.

\section{Hypertension and other factors}

Patients with Dislipidemia (32\%) had higher prevalence of hypertension than without Dislipidemia ( $44 \%$ vs $30 \%$ ) Similar finding were found between overweight participants (26\%) and normal weight participants (46\% vs $34 \%$ ). This is in accordance with previous findings (Shamail Zafar, 2007).

\section{CONCLUSION}

Over all the prevalence of pre- hypertension and the hypertension is probably increasing in Nepal. Awareness, control and treatment rate of hypertension is also improving.
Overall, KAP on hypertension is satisfactory. Factors that were found to influence hypertension are tobacco use, regular exercise, concurrent diabetes, Dislipidemia and weight.

This study was conducted with heart hospital staffs; it can be assumed that they are probably more knowledgeable in comparision to the general public, so, findings of this study may not be representing general public's KAP on hypertension.

\section{ACKNOWLEDGEMENT}

Our special thanks to the staffs of SGNHC, whose active participation and cooperation had given us an encouragement throughout the study. We have special debt of gratitude to Associate Professor Tilak Prasad Chaulagain for his valuable guidance. We would like to thank Mr. Siddhi Vinod Adhikari, Lecture TU, and Tri- Chandra Campus for his continuous support throughout the study. 


\section{REFERENCES}

1. Burt VL, Cutler JA, Higgins SM , etal , 1960. Trends in the prevalence, awareness, treatment , and control of hypertension in the adult US Population. Journal of Hypertension 26(1): 60-9

2. Masliniuk AL, lee CM, Lawes CM, 2007. Hypertension: Its prevalence and population attributable fraction for mortality from cardiovascular disease in the Asia - pacific region, Journal of Hypertension 2007, Jan: 25(1), 73-9

3. Pandey Mr, Upadhyaya LR, Dhungel S, 1981. Prevalence of hypertension in a rural community in Nepal,Indian Heart Journal,NovDec;33(6):284-9 Indian Heart Journal

4. Sharma D, KC M B, Rajbhandari S etal, 2006. Study of prevalence awareness, treatment and control of hypertension in Suburban area of Kathmandu, Nepal. Indian Heart Journal, Jan- Feb; 58(1): 34-7

5. Vokonas PS, Kannel WB,Cupples La ,1988. Epidemiology and risk of hypertension in the elderly : the Framingham study ; Journal of Hypertension6(1):53-9.
6. Capriotti T, Kirby LG, Smeltzer SC 2000 ,unrecognized high blood pressure. A major public health issue for the workplace. AAOHB J,2000,Jul;48:338-43

7. Sonkodi B, Fodor JG, Abraham G et al2004. Hypertension screening in a salami factory:a worksite hypertension study, Journal of human hypertension,2004,18,567-569

8. Line Aubert, Pascal Bovet, Jean Pierre et al 1998 Knowledge, Attitudes and Practices on Hypertension in a country in epidemiological transition Journal of Hypertension ,1998;31:1136-1145

9. Shamail Z, Israr UI, Anjum R et al2007 Relationship of body mass index and waist to hip ration measurement with hypertension in young adult medical students ,Pakistan Journal of medical science, July-Sep2007, Vol 23, No 4 , 574-579

10. Vaidhy A; Pokhrel Pk, Karki $P$ et al. Exploring the iceberg of hypertension a community based study in an eastern Nepal town. KUMJ 2007, 593:349-359 